\title{
Effects of Maternal Overprotection on Social Competence in Young Children: The Mediating Role of Young Children's Anxiety
}

\author{
Young Sun Chung \\ Assistant Professor, Department of Child and Youth Welfare, Pyeongtaek University, Pyeongtaek, Korea \\ 어머니의 과보호 양육이 유아의 사회적 능력에 미치는 영향: \\ 유아 불안의 매개효과 \\ 정영선 \\ 평택대학교 아동청소년교육상담학과 조교수
}

Objectives: This study aimed to examine the direct and indirect effects of maternal overprotection on the development of young children's social competence through their anxiety. In this study, maternal overprotection was defined as anxiously shielding their young children from having negative experiences and maintaining developmentally inappropriate intrusive and permissive parenting for their children.

Methods: Participants were 183 mothers and 18 teachers with young children aged from four to six years. Mothers rated themselves on the degree of their overprotecting behaviors measured by a maternal overprotection scale for young children (Y. S. Chung \& Park, 2021). Teachers rated young children's anxiety and social competence. Data were analyzed using descriptive statistics, correlation analysis, and a structural equation model. Bootstrapping method was applied to examine the significance of the mediating effects.

Results: First, there were significant correlations between maternal overprotection, young children's anxiety and social competence. Second, structural equation modeling supported the hypothesized relations among maternal overprotection, young children's anxiety and social competence after controlling with young children's gender, maternal academic background, and monthly household income. And the level of young children's anxiety mediated the relationship between overprotective parenting and young children's social competence.

Conclusion: This study showed that mother's overprotective parenting was associated with varying levels of young children's anxiety and social competence. Additionally the maternal overprotection linked with children's social competence indirectly through their anxiety. These findings offer basic knowledge applicable to parent education and the for the development of program for improving parenting behaviors. The limitations and other implications of this study are also discussed.

Keywords: overprotection, social competence, anxiety, social skills, young children

Corresponding Author: Young Sun Chung, Department of Child and Youth Welfare, Pyeongtaek University, 3825 Seodong-daero Pyeongtaek-si Gyeonggi-do, Korea

E-mail: yschung@ptu.ac.kr
(c)The Korean Association of Child Studies

This is an Open Access article distributed under the terms of the Creative Commons Attribution Non-Commercial License (http:// creativecommons.org/licenses/by-nc/4.0) which permits unrestricted noncommercial use, distribution, and reproduction in any medium, provided the original work is properly cited. 


\section{Introduction}

유아기는 자율성과 주도성을 키우는 시기이다(Erikson, 1963). 이 시기에 부모는 건강과 안전을 위해 유아를 보호하지만, 이 러한 보호적 행동이 연령과 발달에 적합하지 않게 이루어지 면 유아의 자율성과 주도성을 저해할 수 있다. 인간은 태어나 면서부터 일상생활 속에서 여러 도전을 만나고 대처하면서 성 장한다(Moreland \& Dumas, 2008). 유아기의 도전은 스스로 옷 을 입고, 양육자와 분리되어 유치원이나 어린이집에 가고, 집 단 환경 속에서 또래와 장난감을 공유하고 규칙을 배우는 것 등을 포함한다. 그런데 과보호 양육을 하는 부모는 유아의 도 전에 포함된 위험과 어려움을 앞서 걱정하며 자녀의 행동과 환경을 제한하거나 대신 그 일을 해주기 때문에, 유아는 성장 할 수 있는 기회를 놓치게 된다. 과보호 양육을 받은 유아는 세 상은 안전하지 않다는 불안과 걱정을 내면화하고 일상의 도전 과 문제에 대처하는 기술과 유능감을 충분히 발달시키지 못하 여 사회적으로 미성숙할 수 있다(Edwards, Rapee, \& Kennedy, 2010; Rubin, Coplan, \& Bowker, 2009).

과보호 양육이 자녀의 사회적 발달에 미칠 수 있는 부정적 영향의 가능성에도 불구하고 유아를 대상으로 한 연구는 소 수에 불과하다. 과보호 양육의 영향에 대한 연구는 주로 청소 년 및 성인 초기 자녀를 대상으로 이루어졌다(K. M. Chung \& Yoon, 2015; Perez, Nicholson, Dahlen, \& Leuty, 2020). 하지 만 부모의 과보호 양육은 자녀가 어릴 때부터 나타나는 경 향이 있으며, 부모는 이러한 태도를 이후에도 지속하기 때 문에(Laurin, Joussemet, Tremblay, \& Boivin, 2015; LeMoyne \& Buchanan, 2011) 본 연구에서는 과보호 양육을 유아가 부정적 경험을 하는 것을 걱정하고 보호하여 발달에 적합하지 않게 통제하고 허용하는 양육태도로 정의하고(Y. S. Chung \& Park, 2021), 유아의 사회적 발달에 미치는 과보호 양육의 영향을 살 펴보고자 한다.

어머니의 과보호 양육은 사회화 과정을 통해 유아의 사 회적 능력에 부정적 영향을 미칠 수 있다(Rubin, Burgess, \& Hastings, 2002). 과보호 양육을 하는 부모는 유아가 일상 속에 서 스스로 해결을 시도해볼 수 있는 문제를 앞서 도와주거나 문제 자체를 제거하기도 한다. 이러한 부모는 자녀에게 연령 에 적합한 비계설정을 해주지 못해 유아가 자신을 조절하고 사회적으로 건설적인 행동에 대해 학습할 기회를 제한하며, 그로 인해 유아가 사회적 갈등에 대처하는 전략을 발달시키지 못할 수 있다(Eisenberg, Taylor, Widaman, \& Spinard, 2015). 또 한 허용 수준이 높은 과보호 양육은 유아가 좌절 상황에서 부
적절하게 행동하는 것에 대해 훈육하는 것을 회피하거나 부정 적 정서를 경험하지 않게 원하는 바를 미리 파악하고 해주어 유아의 자기조절능력 발달을 저해할 수 있다. 관련 연구에서 과제를 대신 해주는 어머니의 행동은 유아가 어려움을 딛고 숙달하고자 하는 동기를 감소시키고(L. Kim, 2017), 좌절했을 때 쉽게 포기하는 것과 관계가 있었다(Jang, 2016).

최근 국내에서 어머니의 과보호 양육과 유아의 사회적 능 력의 관계를 살펴보는 연구들이 시작되고 있다. J. Kim의 연구 (2020)에서 자녀가 원하는 대로 해주고 통제하지 않는 어머니 의 과보호 및 허용 양육은 유아가 자신을 조절하는 능력에 부 적 영향을 미치고, 공격성을 비롯한 외현화 행동문제에 정적 영향을 미쳤다. 반대로 어머니가 유아 행동에 대한 한계와 규 칙을 형성하는 양육은 유아가 자기조절능력을 발달시키는데 긍정적인 영향을 미쳤다. Byoun과 Shin의 연구(2021)에서 어머 니의 과보호 양육은 유아가 사회적으로 수용되거나 승인되는 행동을 하지 못하는 사회적 미성숙 수준을 높이고, 또래와 부 적절한 상호작용을 하는 모습으로 이어졌다. S. Lee와 Kang의 연구(2018)에서도 어머니의 과보호 양육은 또래와의 놀이 상 호작용이 감소하고 놀이방해와 단절이 증가하는 부적절한 사 회적 행동과 관계가 있었다. 이러한 선행연구들의 결과를 종합 해보면, 과보호하는 어머니의 양육태도는 유아가 자신을 조절 하고 사회적 상황에서 다른 사람과 적절하게 상호작용하는 사 회적 능력에 부정적 영향을 미친다는 것을 예측해볼 수 있다.

하지만 일부 연구에서는 과보호 양육이 유아의 사회적 능력 에 미치는 부정적 영향을 발견하지 못하였다. 2008년 한국아 동청소년종합실태조사에서는 연구진이 제작한 3 개 문항을 통 해 어머니의 과보호 양육을 측정하였다. 자료를 분석한 결과, 연구자의 가설과 반대로 어머니의 과보호 양육은 만 3세 5 세 유아의 언어, 사회성, 정서발달과 정적인 관계가 있었다(I. J. Chung, 2012). 만 4, 5세 유아를 대상으로 한 O. B. Kim의 연구 (2014)에서 Doh와 Falbo (1999)의 과보호 질문지로 측정한 어 머니의 과보호 양육은 유아의 정서적 능력과 유의한 관계가 없 었다. 연구 결과들이 상충되는 이유 중 하나는 선행연구들에서 과보호를 측정할 때, 국외 도구, 대상 연령에 맞지 않은 도구, 타당화 하지 않은 도구를 사용하는 경우가 대부분이기 때문이 다(Ryoo \& Shin, 2018). 과보호 양육의 모습은 연령과 문화에 따라 다르게 나타날 수 있기 때문에 본 연구에서는 유아 자녀 를 둔 어머니를 대상으로 국내에서 개발되고 타당화한 과보호 양육척도를 사용하여 어머니 과보호 양육과 유아의 사회적 능 력 간의 관계를 살펴보고자 한다(Y. S. Chung \& Park, 2021).

한편 불안은 정의하기 쉽지 않은 심리학 용어 중 하나이지 
만, 유아의 불안은 두려운 정서 반응으로 표현된다. 두려움은 위협이 된다고 여겨지는 사람이나 사물 또는 상황이 다가올 것을 예기하거나 현실적으로 다가왔을 때 일어나는 정서이다 (O. B. Chung, 2018). 유아들은 양육자와 분리될 때, 낮선 사 람이나 상황을 만날 때 등과 같이 일상생활에서 불안을 느낄 수 있다. 불안은 누구나 경험하는 감정이지만, 일부 유아는 불 안의 강도와 빈도가 높아 일상의 기능과 적응적 발달을 방해 하며 불안장애로 진단된 유아의 경우 이후 우울 및 공존 질환 으로 연결되는 등 발달에 부정적 영향을 줄 수 있다(H. Lee \& Shin, 2020; Ooi, Nocita, Coplan, Zhu, \& Rose-Krasnor, 2017).

불안 수준이 높은 유아는 그렇지 않은 또래보다 사회적으 로 유능하지 않은 경향이 있다(Kostelnik, Soderman, Whiren, Rupiper, \& Gregory, 2015). Ooi 등(2017)은 평균 5.7세 유아의 사회적 불안이 사회.정서적, 학업적 적응과 관계가 있는지 조 사하였다. 연구 결과, 유아의 불안은 어머니가 평가하는 사회 적 적응 즉, 기관 밖에서 나타나는 유아의 사회적 참여, 또래 와 놀면서 보이는 스트레스, 또래 문제에 부정적인 영향을 미 쳤다. 뿐만 아니라 유아의 불안은 또래 배척, 비사회적 행동과 같은 교사가 평가한 유아의 사회적 부적응과 유의한 관계가 있었다. 사회적으로 불안하고 위축된 유아는 또래와 상호작 용을 시작하고 또래 집단에 들어가고 또래와 갈등을 겪을 때, 부정적 감정을 강하게 느끼고 그로 인해 적절하게 반응하거 나 대처하지 못하여 사회적 능력이 제한될 수 있다(Stewart \& Rubin, 1995; Wilson \& Hughes, 2011). 이들의 망설이는 행동 은 또래로부터 부정적인 반응을 촉발하여 사회적 상황에서 어 려움을 겪게 한다(Rubin, Bowker, Barstead, \& Coplan, 2018).

유아 불안에 관심을 가지고 있는 연구자들은 어머니의 과 보호 양육이 자녀의 정서적 어려움에 미치는 영향에 주목해왔 다. 과보호 양육을 하는 부모의 심리적 기저에는 자녀의 일과 관련하여 불안해하는 마음이 있기 때문에 과보호 양육을 받은 자녀 또한 불안 수준이 높다는 연구 결과가 일관되게 보고되 고 있다(Byoun \& Shin, 2021; Chorpita \& Barlow, 1998; Kiel \& Buss, 2014; Rapee, 2009). 선행연구들을 메타 분석 한 결과에 따르면, 양육의 하위차원 중에서 자녀의 자율성을 저해하는 지나친 관여와 통제 행동이 거부나 온정보다 유아의 불안에 더 영향을 주었다(McLeod, Wood, \& Weisz, 2007). 2세에 측정 된 어머니의 보호적 양육행동은 3 세 때 유아의 불안과 사회적 위축을 예측하여(Kiel \& Buss, 2010, 2014; Kiel, Premo, \& Buss, 2016), 어머니의 과보호 양육은 이른 시기부터 유아의 불안에 영향을 주는 것으로 나타났다(Edwards et al., 2010).

종단 연구들은 어머니의 과보호 양육이 자녀의 불안의 예
측요인이 될 수 있다는 것을 보여준다. Laurin 등(2015)은 2000 여명을 대상으로 한 종단 자료를 이용하여 아동 불안의 궤적 에 영향을 미치는 부모 양육의 하위 유형을 분석하였다. 종단 자료는 아동의 나이가 2.5 세 때 어머니의 양육 유형을, 그리 고 8세 때 아동의 불안 증상을 포함하여 수집되었다. 연구자들 은 어머니의 양육을 온정, 구조, 허용, 강제, 과보호 양육으로 구분하고 약 6 년 뒤 아동의 불안 수준과 관계를 살펴본 결과, 강제와 과보호 양육 유형만이 아동의 불안 수준을 예측하였 다. 그 외의 종단 연구(Bayer, Sanson, \& Hemphill, 2006; Rapee, 2009)에서도 불안하고 보호하는 양육태도가 이후 아동의 불 안을 예측하였으며 이러한 결과는 어머니의 과보호 양육이 초 기 정서적 어려움에 영향을 준다는 것을 보여준다.

가족의 사회화 과정 속에서 부모의 양육태도는 유아의 정 서와 관련된 특성을 형성하고 이는 유아의 사회.정서적 발 달에 영향을 준다. 연구자들은 자녀의 자율성을 저해하는 과 보호 양육이 유아의 사회적 발달로 연결되는 경로를 정서 와 관련된 요인이 매개한다고 제안하였다(Cui, Morris, Criss, Houltberg, \& Silk, 2014). 앞에서 언급된 선행연구들의 결과를 종합해보면, 어머니의 과보호 양육은 유아의 불안 수준을 높 이고 불안이 높은 유아는 제한된 사회적 능력을 보인다. 동시 에 과보호를 받은 유아는 자기조절, 또래관계, 문제해결과 같 은 사회적 발달에서 미숙한 경향이 있다. 이러한 변인 간의 관 계들을 바탕으로 어머니의 과보호 양육이 유아의 사회적 능 력에 직접적으로 영향을 미칠 뿐 아니라, 유아의 불안을 높이 는 것을 통해 사회적 능력에 간접적으로 영향을 줄 수 있다고 추론해볼 수 있다. Wood, Kiff, Jacobs, Ifekwunigwe와 Piacentini (2007)는 부모의 과보호 양육, 만 5-11세 아동의 불안, 그리고 의존적인 문제해결 태도 간의 연쇄적 관계에 대한 가설을 세 우고 검증하였다. 그 결과, 부모에게 과보호 양육을 받은 아동 은 사회적 문제를 스스로 해결하지 못하고 성인에게 의존하는 경향이 있었으며, 이 두 변인 간의 관계를 아동의 불안이 매개 하였다. 또한 자녀의 물건을 대신 치워주고, 지나치게 자주 신 체적으로 애정을 표현하며 유아의 독립적 행동을 방해하는 어 머니의 과보호 양육은 유아의 불안한 성향과 관계가 있었으 며, 2년 뒤 또래관계에서 사회적 기술이 부족한 모습을 예측하 였다(Rubin et al., 2002).

유아기는 영아기와 비교해 사회적 환경이 넓어지고 다양해 지는 시기로 이 시기에 발달된 사회적 능력은 이후에 맺게 될 사회적 관계의 기초가 된다(Kostelnik et al., 2015). 연구자들은 유아의 사회적 능력과 관련된 주요 변인으로 부모의 양육태도 와 유아의 불안한 성향을 꼽는다. Rubin 등(2018)은 사회적 기 
술의 부족을 예측하는 주요 변인으로 유아의 자율성과 주도성 을 침해하고 통제하는 과보호 양육과 유아의 불안을 제안하였 다. 유아기에 정서적으로 취약하고 어머니의 과보호 양육태도 수준이 높은 집단은 이후 아동기에 사회적으로 어려움을 겪을 수 있다(Davis, Votruba-Drzal, \& Silk, 2015). 따라서 본 연구에 서는 취학 전 유아를 대상으로 어머니의 과보호 양육과 유아 의 불안이 유아의 사회적 능력에 미치는 영향에 대해 알아보 고자 한다. 구체적으로 어머니의 과보호 양육이 유아의 사회 적 능력에 미치는 직접적인 영향과 함께 유아의 불안을 높임 으로써 미치는 간접적인 영향을 함께 살펴보고자 한다. 본 연 구의 결과는 현대 사회의 과보호 양육현상을 향한 사회적 우 려가 타당한지에 대한 근거를 제공하고 바람직한 양육방식 형 성을 위한 부모교육에 실증적인 자료가 될 것이다.

\section{연구문제 1}

어머니의 과보호 양육, 유아의 불안과 사회적 능력 간의 관계 는 어떠한가?

\section{연구문제 2}

유아의 불안은 어머니의 과보호 양육이 유아의 사회적 능력 에 미치는 영향을 매개하는가?

\section{Methods}

\section{연구대상}

본 연구는 어린이집 4,5 세 반에 재원 중인 183 명 유아를 대상 으로 하였으며, 해당 유아의 어머니 183 명과 담임교사 18 명을 통해 자료를 수집하였다. 이 시기는 유아 후기로 아직은 학교, 또래집단 등과 같은 가족외 요인보다 가족내 요인, 특히 어머 니의 영향이 상대적으로 큰 시기이며(Shaffer, 2009), 이 시기까 지 Erikson (1963)의 심리사회적 발달단계에 따라 유아는 자율 성과 주도성을 발달시키며, 눈과 손의 협응 능력이 향상되어 혼자서 밥먹기, 옷입기, 세수하기와 같은 자조활동이 가능해 지기 때문에 연구 대상으로 선정하였다.

응답자의 평균 연령은 만 38세(범위: 29-51세, 표준편차: 3.58 세)이었다. 설문지 응답의 대상이 된 유아기 자녀의 평균 월령은 68개월(범위: 58-79개월, 표준편차: 6.00개월)이었으며 남아 101 명, 여아 82 명이었다. 연구대상자의 인구학적 특성은 다음 Table 1 과 같다.

\section{연구도구}

$$
\text { 어머니의 과보호 양육 }
$$

어머니의 과보호적인 양육의 정도를 측정하기 위하여 어머니 과보호 척도(유아용)를 사용하였다(Y. S. Chung \& Park, 2021). 이 척도는 세 개의 하위요인으로 구분되며, 침해(intrusive control) 8 문항, 응석/허용(permissive indulgence) 4 문항 그리고 걱정/보호(anxious protection) 6문항으로 구성되었다. 침해는 유아가 자신의 일을 스스로 할 기회를 제한하고 도와주며 개 입하는 양육태도이며, 응석과 허용은 유아에게 행동 지도가 필요한 상황에서 훈육하지 않는 양육태도, 걱정과 보호는 유 아가 부정적인 경험을 하지 않고 긍정적인 경험만 하게 하려 는 양육태도를 말한다. 어머니는 자신의 양육행동을 바탕으 로 각 문항에 대해 전혀 그렇지 않다(1점) 매우 그렇다(4점) 의 4점 척도로 평정하였다. 문항의 예로는 "아이가 혼자 할 수 있음에도 불구하고 아이를 도와준다.”, "아이가 버릇없이 행 동하더라도 혼내지 않는다.", "아이가 실패로 인한 좌절감을 경험하지 않도록 보호한다.” 등이 있다. 하위영역별 점수는 문항들의 평균 점수를 사용하였으며, 과보호 양육 총점은 하 위영역별 점수를 합산하여 사용하였다. 척도의 내적 합치도 (Cronbach's $\alpha$ )는 .75이며, 하위척도의 내적 합치도는 침해 .76, 응석/허용.65, 걱정/보호.70으로 나타났다.

\section{유아의 불안}

유아의 불안을 측정하기 위해 Spence, Rapee, McDonald와 Ingram의 연구(2001)를 바탕으로 만 3-6세 유아의 불안 수준을 측정하기 위해 개발된 유아 불안 척도(Preschool Anxiety Scale [PAS])의 교사용 질문지를 번안.수정하여 사용하였다. 본 연구 에서는 사회적 불안, 일반화된 불안, 분리불안의 세 하위척도에 포함된 15 문항의 총점을 사용하였다. 교사는 각 문항에 대해 전혀 그렇지 않다(1점) 항상 그렇다(5점)의 5점 척도로 평정하 였으며, 문항의 예로는 "하던 걱정을 그만두는 것을 어려워한 다.”, "낮선 사람과 만나거나 이야기하는 것을 두려워한다." "유 치원에서 부모를 찾으며 운다.” 등이 있다. 척도의 내적 합치도 (Cronbach's $\alpha$ )는 .92이며, 하위척도의 내적 합치도는 사회적 불 안 .85 , 일반화된 불안 .87 , 분리불안 .85 로 나타났다.

유아기 불안은 하위 유형이 명확하게 구분되기보다는 혼 합된 상태로 나타나 불안의 하위요인 간에 뚜렷한 구분이 되 지 않고 불안의 단일 차원을 반영하는 경향이 있다(Egger \& 
Table 1

Demographic Information of Participants

\begin{tabular}{|c|c|c|c|c|c|}
\hline Variables & Categories & $n(\%)$ & Variables & Categories & $n(\%)$ \\
\hline \multirow[t]{2}{*}{ Gender } & Boys & $101(55.2)$ & \multirow[t]{2}{*}{ Maternal academic background } & High school & $1(0.5)$ \\
\hline & Girls & $82(44.8)$ & & University & $154(84.2)$ \\
\hline \multirow[t]{3}{*}{ Age } & 4-year-old & $18(9.8)$ & \multirow{6}{*}{$\begin{array}{l}\text { Monthly household } \\
\text { income before tax } \\
(10,000 \text { won })\end{array}$} & Graduate school & $28(15.3)$ \\
\hline & 5-year-old & $102(55.7)$ & & Less than 499 & $15(8.2)$ \\
\hline & 6-year-old & $63(34.4)$ & & Over 500-599 & $32(17.5)$ \\
\hline \multirow[t]{3}{*}{ Birth-order } & First or only & $126(68.9)$ & & Over 600-799 & $43(23.5)$ \\
\hline & Second & $46(25.1)$ & & More than 800 & $93(50.8)$ \\
\hline & Third & $11(6.0)$ & & & \\
\hline
\end{tabular}

Note. $N=183$.

Angold, 2006; Howard, Muris, Loxton, \& Wege, 2017). 또한 본 연구 자료를 바탕으로 요인분석을 한 결과, 불안의 3요인 모형 은 통계적으로 적합하지 않았다 $\left(\chi^{2} / d f=5.51, \mathrm{CFI}=.76, \mathrm{TLI}=\right.$ $.72, \mathrm{RMSEA}=.16, \mathrm{SRMR}=.10)$. 따라서 본 연구에서는 각 문 항 점수를 합산한 총점을 사용하였으며, 점수가 높을수록 유 아의 불안 수준이 높다는 것을 의미한다.

\section{유아의 사회적 능력}

유아의 사회적 능력을 측정하기 위하여 Gresham과 Elliott (1990)이 개발한 유아용 사회적 기술 척도(Social Skill Rating System for preschool level [SSRS])를 사용하였다. 이 척도에서 사회적 능력은 사회적으로 용인되지 않는 행동들을 하지 않고 다른 사람과 효과적으로 상호작용하도록 이끌어 내는 능력으 로, 사회적으로 수용되고 유능한 행동들로 정의한다. 이 척도 는 협동/순응 10 문항, 자기 주장 10 문항, 자아 통제 10 문항의 총 30 문항으로 구성되었다. 교사는 각 문항에 대해 전혀 그렇 지 않다(1점) 자주 그렇다(3점)의 3점 척도로 측정하며, 문항 의 예로는 “시키지 않아도 친구들과 협력한다.", “또래에게 놀 림을 당하는 경우 적절하게 대응한다.”, “친구들과 갈등이 있 을 때 잘 참는다.” 등이 있다. 각 문항 점수를 합산한 총점을 사 용하였으며, 점수가 높을수록 유아의 사회적 능력이 높다는 것을 의미한다. 척도의 내적 합치도(Cronbach's $\alpha$ )는 .95이며, 하위척도의 내적 합치도는 협동/순응 .87 , 자기 주장 .88 , 자아 통제 .88로 나타났다.

\section{통제변인}

본 연구에서는 독립변인 외에 종속변인에 영향을 줄 수 있는
인구학적 변인을 통제하고자 하였다. 이에 본 연구대상 유아 의 성별, 연령, 출생순위, 어머니의 학력, 가구 총 월수입에 따 라 주요 변인에 차이가 있는지 살펴보기 위해 독립표본 $t$ 검증 과 일원분산분석을 실시하였다. 그 결과 유아의 성별, 어머니 의 학력, 가구 총 월수입에 따라 유아의 사회적 능력에서 유의 한 차이가 발견되었다. 유아의 사회적 능력 점수는 여아가 남 아보다 유의하게 높았으며 $(t=-2.15, p<.05)$, 어머니의 학력이 대학교 졸업 이하인 집단이 대학원 졸업 이상인 집단보다 유 의하게 높았고 $(t=2.40, p<.05)$, 가구 총 월수입이 세전 500 만 원 미만인 집단보다 500 만원 이상인 집단들이 유의하게 높았 다 $(F=5.92, p=.001)$. 따라서 추후 분석과정에서는 유아의 성 별, 어머니의 학력, 가구 총 월수입을 통제변인으로 포함하여 분석하였다.

\section{연구절차}

어린이집 만 4,5 세 반 교사 2 명과 어머니 2명에게 예비조사를 실시하였으며, 질문지 문항의 내용을 이해하고 응답하기에 무 리가 없다는 것을 확인하였다. 연구대상 선정을 위해 서울과 경기도에 위치한 어린이집 10 곳을 섭외하여 연구 설명문과 함께 연구 참여 동의서를 가정으로 배부하였다. 연구 참여에 동의한 어머니와 교사에게만 설문지를 배부하였으며, 어머니 설문지 183 개, 교사 설문지 201 개가 회수되었다. 본 연구는 한 아동에 대한 어머니와 교사 보고 설문지가 모두 회수된 183세 트의 설문지를 분석에 활용하였다.

\section{자료분석}

본 연구의 자료는 Mplus 8.3 (Muthén \& Muthén, 1998-2017)과 
Table 2

Descriptive Statistics of Observed Continuous Variables

\begin{tabular}{|c|c|c|c|}
\hline Variables & $M$ & $S D$ & Range \\
\hline Social competence & 71.87 & 12.14 & $37.00-90.00$ \\
\hline Cooperation & 25.05 & 4.09 & $14.00-30.00$ \\
\hline Assertiveness & 23.49 & 4.68 & $11.00-30.00$ \\
\hline Self-control & 23.33 & 4.48 & $11.00-30.00$ \\
\hline Anxiety & 24.70 & 9.20 & $15.00-54.00$ \\
\hline Maternal overprotection & 6.61 & .52 & $3.71-9.79$ \\
\hline Intrusiveness & 2.42 & .51 & $1.13-3.50$ \\
\hline Permissive indulgence & 1.73 & .55 & $1.00-3.25$ \\
\hline Anxious protection & 2.47 & 1.01 & $1.17-3.92$ \\
\hline
\end{tabular}

Note. $N=183$.

SPSS 25.0 (IBM Co., Armonk, NY) 프로그램을 사용하였다. 기 술통계분석, 차이검증, 상관관계분석 등의 기본적인 통계분 석 외에 연구 모형을 검증하기 위한 경로분석, 매개효과의 유 의성을 검증하기 위한 편향 수정 부트스트레핑(bias corrected bootstrapping)방법을 실시하였다.

\section{Results}

\section{측정변인의 일반적 경향}

본 연구에서 측정한 유아의 사회적 능력, 불안 및 어머니의 과보호 양육의 평균, 표준편차, 최소값에서 최대값의 범위를 Table 2에 제시하였다. 어머니 과보호 양육의 하위 척도 점수 를 살펴보면, 4 점 척도에서 침해의 평균은 2.42 점, 걱정/보호 는 2.47 점, 응석/허용은 1.73 점으로 나타났다. 이러한 결과는 연구에 참여한 어머니들이 평균적으로 침해와 걱정/보호 문 항에 대해 별로 그렇지 않다(2점)에서 가끔 그렇다(3점) 사이 의 응답을 하였으며, 응석/허용 문항에 대해서는 별로 그렇지 않다(2점) 미만의 응답을 하였다는 것을 보여준다.

\section{측정변인 간의 상관관계}

경로분석을 실시하기 전에 유아의 사회적 능력, 불안 및 어머 니의 과보호 양육의 상관관계를 확인하기 위해 Pearson의 적 률상관분석을 실시하였으며, 결과를 Table 3에 제시하였다. 유 아의 사회적 능력은 어머니의 과보호 양육과 부적 상관관계가 나타났으며 $(r=-.24, p<.01)$, 유아의 불안과도 부적인 상관관
계가 있었다 $(r=-.33, p<.001)$. 또한 어머니의 과보호 양육과 유아의 불안 간에는 유의한 정적 상관관계가 나타났다 $(r=.18$, $p<.05)$.

\section{구조모형 분석}

본 연구에서는 어머니의 과보호 양육이 유아의 사회적 능력에 미치는 영향에서 유아 불안의 매개 경로를 검증하였으며, 유 아의 사회적 능력과 관련하여 유의한 차이를 보인 유아의 성 별, 어머니의 학력, 가구 총 월수입을 통제하고 분석하였다.

먼저 어머니의 과보호 양육이 유아의 불안을 매개로 사회 적 능력에 미치는 영향을 확인하기 위하여 설정된 연구모형을 분석하였다. 본 연구의 모든 변인들은 왜도가 \pm 2 , 첨도가 \pm 7 을 넘지 않았기에 정규성 가정을 크게 위배하지 않는 것으로 나 타났다(West, Finch, \& Curran, 1995). 모형 적합도를 판단하기 위해 적합도와 간명성을 동시에 고려하는 RMSEA, CFI, TLI 와 SRMR 지수를 이용하였다. 이에 대한 결과를 Table 4에 제 시하였다. 구조모형의 적합도는 $\chi^{2} / d f=1.23, \mathrm{CFI}=.99, \mathrm{TLI}=$ $.98, \mathrm{RMSEA}=.04, \mathrm{SRMR}=.05$ 로 나타나 본 연구모형은 적합 하다고 할 수 있다.

다음으로 각 변인 간의 경로를 살펴보았으며, 그 결과는 Table 5에 제시하였다. 어머니의 유아의 사회적 능력에 대한 어머니의 과보호 양육 $(\beta=-.20, p<.01)$ 과 유아의 불안 $(\beta=-.30$, $p<.01)$ 의 경로는 통계적으로 유의하였으며, 어머니의 과보호 양육과 유아의 불안 간의 경로도 통계적으로 유의하였다 $(\beta=$ $.23, p<.001)$. 즉 어머니의 과보호 양육은 유아의 불안에 정적 인 영향을, 유아의 사회적 능력에는 부적인 영향을 미쳤고 유 아의 불안은 유아의 사회적 능력에 부적인 영향을 미쳤다. 
Table 3

Correlations Among Variables

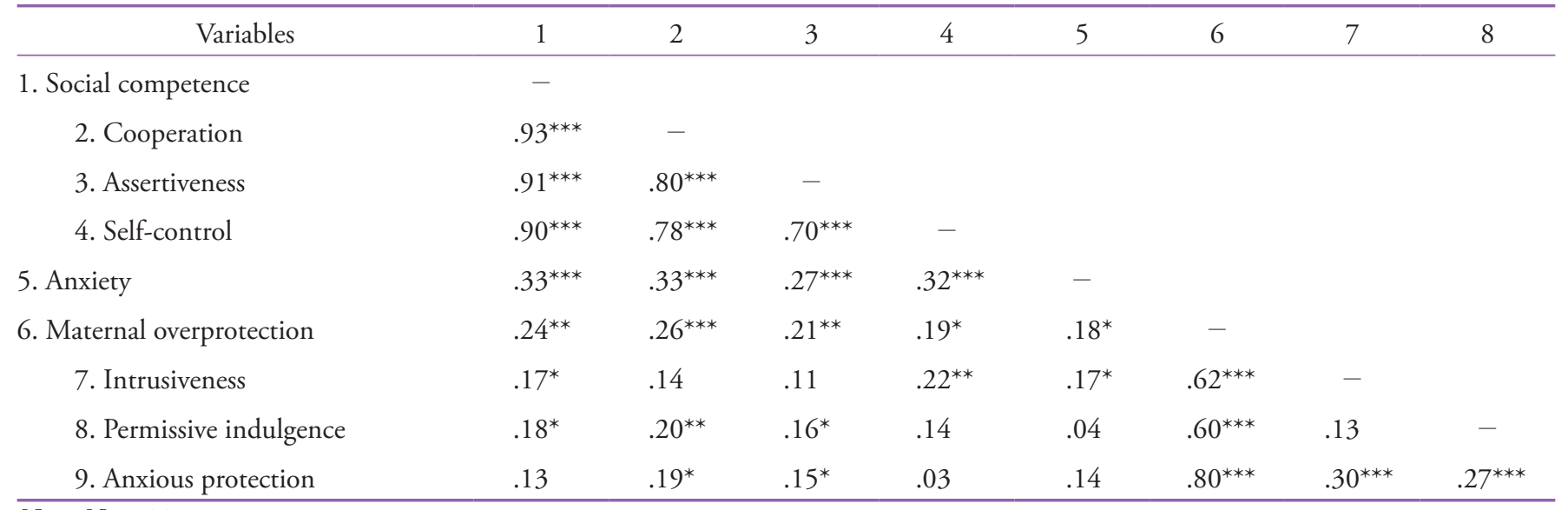

Note. $N=183$.

${ }^{*} p<.05 .{ }^{* *} p<.01 .{ }^{* * *} p<.001$.

Table 4

Fit Index of Observed Model

\begin{tabular}{cccccc}
\hline$\chi^{2}$ & $\chi^{2} / d f$ & CFI & TLI & RMSEA & SRMR \\
\hline 35.81 & 1.23 & .99 & .98 & .04 & .05 \\
$(d f=29, p=0.18)$ & & & & .90 C.I. $(.00, .07)$ & \\
\hline
\end{tabular}

Note. $N=183$.

Table 5

Path Estimate of Research Model

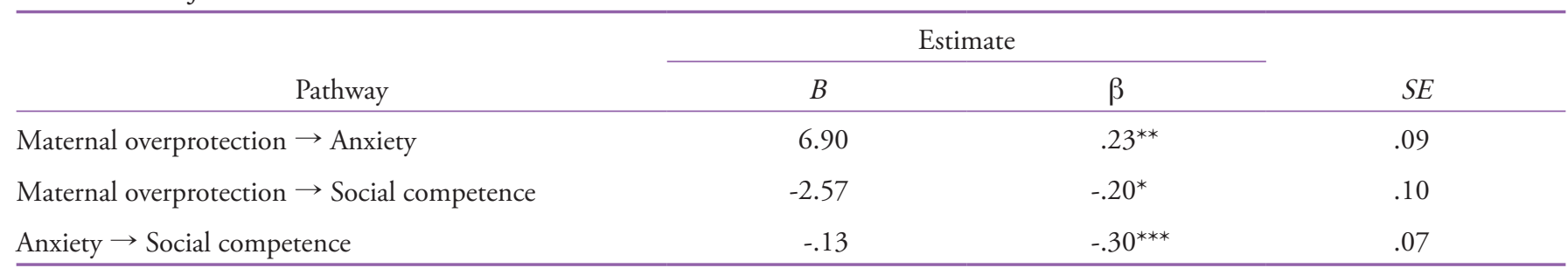

Note. $N=183$.

${ }^{*} p<.05 .{ }^{* *} p<.01 .{ }^{* * *} p<.001$.

\section{매개효과 검증}

어머니의 과보호 양육과 유아의 사회적 능력 간의 관계에서 유아 불안의 매개효과가 통계적으로 유의한지 검증하기 위해 편향 수정 부트스트래핑을 실시하였다. 해당 방법은 표본재추 출 횟수가 많을수록 안정적인 신뢰구간을 얻을 수 있으므로 10,000 회를 실시하였다. 부트스트래핑을 통한 매개효과 검증 은 하한한계와 상한한계 사이에 0이 포함되지 않을 경우 유의 한 것으로 본다(S. Kim, 2016).

본 연구 모형의 직접효과 및 간접효과, 총효과는 Table 6에
제시하였다. 먼저 어머니의 과보호 양육이 유아의 사회적 능 력에 영향을 미치는 경로에서 총효과는 $95 \%$ 신뢰구간(CI)에 서 하한값 -8.56 , 상한값 -.49로 0 을 포함하지 않아 통계적으로 유의하게 나타났다. 다음으로 어머니의 과보호 양육이 유아 불안을 통해 유아의 사회적 능력에 미치는 영향에서 간접효과 를 검증하였을 때, $95 \%$ 신뢰구간 $(\mathrm{CI})$ 에서 하한값 -2.08 , 상한 값 -.08로 0을 포함하지 않아 통계적으로 유의하게 나타났다. 따라서 어머니의 과보호 양육이 유아의 사회적 능력에 미치는 영향에서 유아 불안의 매개효과는 유의하다고 볼 수 있다. 
Table 6

Standardized Direct, Indirect, and Total Effects of Model

\begin{tabular}{cccc}
\hline Pathway & Direct effect & $\begin{array}{c}\text { Indirect effect } \\
(\text { SE, 95\% CI })\end{array}$ & Total effect \\
\hline $\begin{array}{c}\text { Maternal overprotection } \\
\text { Social competence }\end{array}$ & -.20 & $-.07^{*}$ & $-.27^{*}$ \\
\hline
\end{tabular}

Note. $N=183$.

${ }^{*} p<.05$.

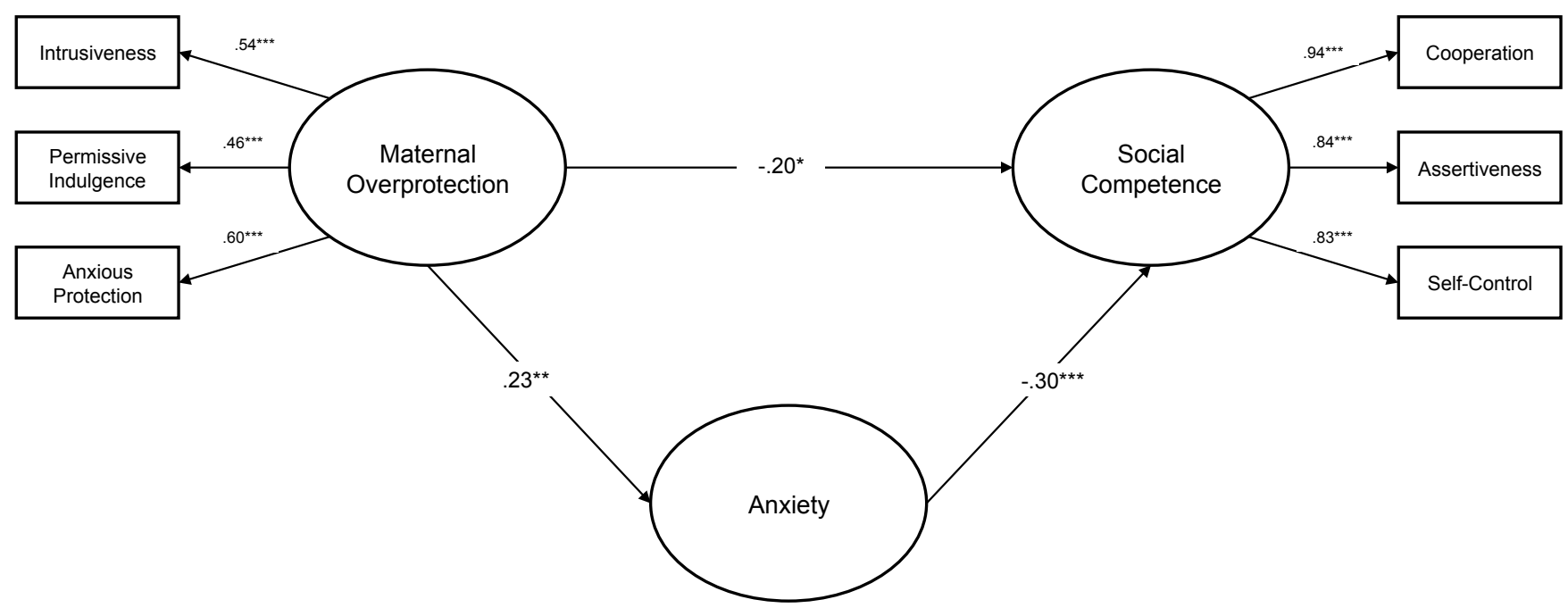

Figure 1. Results of structural equation model.

${ }^{*} p<.05 .{ }^{* *} p<.01 .{ }^{* * *} p<.001$.

이상의 분석 결과를 바탕으로 검증된 연구모형의 경로계수 를 Figure 1에 제시하였다.

\section{Discussion}

본 연구는 유아기 자녀를 둔 어머니를 대상으로 어머니의 과 보호 양육이 자녀의 사회.정서적 발달에 미치는 영향을 밝히 고자 하였다. 구체적으로 어머니의 과보호 양육이 유아의 사 회적 능력에 미치는 직접적 영향과 유아의 불안을 통한 간접 적 영향을 살펴보았다. 본 연구의 주요 결과를 요약하고 이를 논의하면 다음과 같다.

첫째, 어머니의 과보호 양육은 유아의 불안에 정적 영향을 미치는 것으로 나타났다. 이러한 결과는 어머니의 과보호 양 육이 유아의 불안 수준을 높일 수 있다는 선행연구 결과와 일 치하며(Kiel \& Buss, 2014; H. Lee \& Shin, 2020), 어머니의 과 보호 양육이 국내 선행연구에서 주로 다루어진 분리불안뿐만
아니라 사회적 상황, 낯선 사람 등과 같은 전반적인 불안 수준 에 영향을 미친다는 것을 보여준다(J. Lee \& Han, 2019; Ryoo \& Shin, 2018). 과보호하는 부모는 지나친 걱정으로 낮은 수준 의 위협 요인에도 예민하게 반응하고, 이러한 부모의 양육 반 응이 누적되면 유아도 모호한 상황을 부정적이고 위험한 것으 로 해석하여 불안하고 위축될 수 있다(Kiel \& Buss, 2014). 또한 유아는 도전적인 일, 또래갈등, 실수와 같은 어려움을 시행착 오를 통해 스스로 해결함으로써 자신의 능력에 대한 자신감을 높인다. 하지만 과보호 양육은 유아가 스스로 문제를 해결할 기회를 제한하기 때문에 유아의 유능감을 저하시켜 불안 수준 을 높일 수 있다(Chorpita \& Barlow, 1998).

불안은 유아기에 나타나는 대표적인 내면화 행동문제이 며, 유아의 불안은 신체화 증상, 타인과의 상호작용의 어려움 등과 같은 적응적 어려움과 연결된다(Ryoo \& Shin, 2018). 또 한 유아기 높은 불안 수준은 이후 우울 및 불안 장애의 전조가 될 수 있기 때문에 과보호 양육이 유아의 불안에 영향을 미친 다는 연구 결과는 과보호와 관련하여 부모의 양육태도에 대한 
조기 점검 및 개입이 필요하다는 것을 보여준다. 실제로 영유 아기 부모를 대상으로 부모교육을 실시하였을 때 부모의 과보 호 양육과 자녀의 분리불안 수준이 감소하였다(Mayer-Brien, Turgeon, \& Lanovaz, 2017). 이러한 양육의 조기 개입에 따른 긍정적인 효과는 영유아기 부모의 바람직한 양육태도 형성의 필요성과 효과를 보여준다.

둘째, 어머니의 과보호 양육은 유아의 사회적 능력에 부적 영향을 미쳤다. 본 연구에서 나타난 어머니의 과보호 양육이 유아의 사회적 능력에 미치는 직접적인 영향은 국내 선행연구 결과들과 일치하며(Byoun \& Shin, 2021; J. Kim, 2020; S. Lee $\&$ Kang, 2018), 유아의 자율성을 제한하는 양육태도인 심리 적 통제와 침해에 대한 연구 결과들과 유사한 맥락을 갖는다 (Eisenberg et al., 2015; Jang, 2016; L. Kim, 2017). 유아는 다양한 사회적 행동을 해보고 주변 사람들로부터 피드백을 받아 사회 적으로 적절한 행동이 무엇인지 학습하고 사회적 기술을 발달 시키는 경험이 필요하다. 자녀가 겪을 어려움에 대해 지나치 게 반응하고 염려하는 어머니의 양육태도는 이러한 경험을 제 한하여 유아가 문제 상황을 극복하는 대처와 숙달의 기회를 방해하며, 사회적 상황에서 의존적이고 수동적으로 대처하게 함으로써 유아의 사회적 능력 발달을 제한할 수 있다(Rubin et al., 2018).

한편 본 연구의 변인간 상관관계 분석 결과를 살펴보면, 과 보호 양육의 하위요인별로 불안과 사회적 능력과의 상관관계 가 다르게 나타났다. 일부 연구자들은 부모의 통제적 수준에 따라 과보호 양육이 야기하는 발달적 결과는 서로 다를 수 있 다고 제안한다(Kiel \& Buss, 2010; Thomasgard, Metz, Edelbrock, \& Shonkoff, 1995). 통제적 수준이 높은 침해적 과보호 양육 을 받은 유아는 자신이 결정하거나 스스로 문제를 해결한 경 험이 부족하기 때문에 의존적이고 자기 효능감이 부족하여 (Eisenberg et al., 2015) 이후 불안과 우울 같은 정서적 어려움을 겪을 수 있다(Laurin et al., 2015). 본 연구에서도 과보호 양육의 하위요인 중 침해하는 과보호 양육만이 유아의 불안과 유의한 관계가 나타났다. 단순 상관관계의 분석 결과로 변인의 통계 적 영향력을 해석할 수는 없지만, 과보호 양육의 하위유형에 따라 발달적 결과에 차이가 있을 수 있는 가능성을 조심스럽 게 생각해볼 수 있다. 추후 연구에서는 이러한 가능성을 포함 한 연구 모형을 설정하여 과보호 양육의 복합적인 영향을 살 펴볼 수 있다.

셋째, 부모의 과보호 양육이 유아의 사회적 능력에 미치는 영향에서 유아의 불안의 매개효과가 유의한 것으로 나타나 부 모의 과보호 양육은 유아의 불안을 매개로 유아의 사회적 능
력에 영향을 미친다는 가설을 지지하였다. 이러한 연구 결과 는 유아의 불안을 통한 어머니의 과보호 양육과 유아의 사회 적 문제해결능력 간의 관계를 검증한 Wood 등(2007)의 연구 와 일맥상통한다. 기존의 과보호 양육 연구들은 유아의 사회 적 능력보다 불안, 위축과 같은 심리적 어려움에 더 초점을 맞 추고 있었다(Kiel et al., 2016; Rapee, 2009; Ryoo \& Shin, 2018). 본 연구는 과보호 양육으로 불안 수준이 높아진 유아들이 사 회적 능력에서도 제한받을 수 있다는 결과를 제시함으로써 과 보호 양육과 유아의 사회성 간의 관계에 대한 경험적 증거를 제시하였다.

적절한 양육은 자녀의 안전을 위해 보호하고 자녀의 발 달을 위해 시행착오의 기회를 제공하는 것 모두 필요하다 (Grolnick, Caruso, \& Levitt, 2019). 유아기는 부모의 보호적인 역할이 필요한 시기이며, 두려움을 많이 느끼는 기질의 유아 에게는 민감한 양육이 보호적 행동으로 나타날 수 있다. 하지 만 어떤 사람도 긍정적인 경험만 하고 부정적인 경험을 하지 않고 살 수 없기 때문에 부모는 어려움에 대처할 수 있는 자녀 의 능력을 키우는 양육 또한 제공하는 것이 적절하다. 또한 일 상의 도전과 어려움을 스스로 극복했을 때 유아의 자율성과 주도성은 향상된다. 연구자들은 부적절하게 허용하고 통제하 는 과보호적 양육현상의 배경에는 개인적 요인과 사회적 요인 이 있다고 제안한다. 우선 유아의 성별과 기질, 부모의 심리적 특성 등과 같은 개인적 특성이 부모의 과보호 양육의 정도와 형태에 영향을 줄 수 있다(Shin \& Lee, 2016). 또한 미디어에 서 제공하는 정보는 자녀 양육에 영향을 크게 미치고 있다. 미 디어를 통해 전달되는 사건 및 사고 소식과 검증되지 않은 광 고성 양육 정보는 부모들을 불안하게 하고, 자녀의 미래를 위 해 어린 시절부터 적극적으로 개입하고 관리해야 한다는 생각 을 강화할 수 있다. 하지만 구체적으로 어떤 개인적 혹은 사회 적 요인들로 인해 부모들이 과보호 양육을 하게 되는지에 대 한 연구는 미진하여 이에 대한 후속 연구를 통해 오늘날 부모 들의 양육 현상의 배경을 이해하고 긍정적인 양육문화 형성을 도모할 필요가 있다.

마지막으로 상기한 논의를 바탕으로 본 연구의 제한점을 제시하고 후속 연구를 위한 제언을 하고자 한다. 첫째, 표집에 따른 연구 결과 일반화와 관련된 제한점이 있다. 연구대상인 어머니의 $95.5 \%$ 가 대학교 졸업 이상의 학력을 가지고 있으며, $50.8 \%$ 에 해당하는 가구가 총 월수입 800 만원 이상이었다. 가 구 총 월수입이 높은 이유 중 하나는 대상 어머니의 $78 \%$ 가 취 업모로 맞벌이 가구의 비중이 높기 때문인 것으로 추측된다. 따라서 다양한 인구학적 특성을 포함한 표집이 이루어지지 않 
았다는 한계가 있으며, 본 연구의 결과를 해석할 때 사회.경제 적 수준이 높은 집단이 표집되었다는 점을 고려해야 한다. 과 보호 양육현상은 가족의 사회경제적 지위에 따라 그에 따른 영향이 다를 수 있기 때문에(I. J. Chung, 2012; Shaffer, 2009) 후 속 연구에서는 다양한 인구학적 특성을 고려한 표집 대상으로 과보호 양육현상을 연구할 필요가 있다.

둘째, 본 연구는 횡단적 자료에 기초하여 분석되었기 때문 에 어머니의 과보호 양육과 유아의 불안의 상관관계를 해석하 는데 주의를 기울일 필요가 있다. Kiel과 Buss (2014)의 연구에 서 두려움을 쉽게 느끼는 기질의 영아의 경우, 해당 영아의 어 머니는 다른 기질의 영아 어머니보다 과보호적인 양육태도를 더 많이 보였으며, 국내 연구(H. Lee \& Shin, 2020)에서도 행동 억제 수준이 높은 유아의 어머니가 자녀에게 필요 이상의 도 움을 제공하는 과보호적 양육태도를 보였다. 선행연구들은 위 축 및 수줍음과 같은 유아의 특정 기질이 부모가 자녀를 과보 호하게 한다고 제안한다. 본 연구에서도 불안 수준이 높은 유 아의 기질적 특성이 부모의 과보호에 영향을 주었을 가능성도 배제할 수 없기 때문에 후속 연구에서는 종단적 연구설계를 통해 두 변인 간 상호적인 영향을 살펴볼 필요가 있다.

셋째, 과보호 양육을 어머니로 한정하여 살펴보았다는 연 구의 제한점이 있다. 본 연구는 과보호 양육을 측정하기 위해 상대적으로 양육에 참여하는 시간이 긴 어머니만을 대상으 로 연구하였다. 그러나 최근에는 아버지의 양육참여가 증가하 면서 유아의 발달에 아버지 양육의 기여도도 커지고 있으며 (M. Lee \& Choi, 2014), 양육 유형에 따른 영향도 아버지와 어 머니가 다르다는 연구 결과들이 있다(Beato, Pereira, Barros, \& Muris, 2016). 또한 어머니와 아버지의 과보호 양육은 서로 영 향을 주고 받는 상대방 효과가 존재한다는 종단연구 결과도 보고되고 있어(Brenning, Soenens, van Petegem, \& Kins, 2017), 과보호 양육에서 아버지를 포함하여 연구할 필요가 있다.

이러한 제한점에도 불구하고 본 연구는 다음 두 가지 측면 에서 의의가 있다. 우선 그동안 연구가 미진했던 과보호 양육의 초기 영향을 밝혀 유아기 발달에 바람직한 양육 방향은 무엇인 지 제시하고자 했다는 점에 그 의의가 있다. 또한 과보호 양육 은 자녀의 연령에 맞게, 문화에 맞게 적절하게 측정되어야 하며, 그렇지 않을 경우 연구 결과가 왜곡될 수 있다(Y. S. Chung \& Park, 2021). 본 연구는 유아기 자녀를 둔 어머니를 대상으로 국 내에서 개발되고 타당화된 척도를 사용하여 연구 모형을 검증 하였다는 점에서 의의가 있다. 결론적으로 유아 자녀에 대한 부 모의 과보호 양육은 유아의 사회적 능력에 직접적으로 부정적
영향을 미칠 뿐 아니라 유아의 불안 수준을 높임으로써 간접적 으로 유아의 사회적 능력의 발달을 제한할 수 있다.

\section{Acknowledgements}

This study was supported by the 2020 research grant of the Korean Association of Child Studies.

\section{Notes}

This article was presented at the 2021 Annual Spring Conference of the Korean Association of Child Studies.

\section{Conflict of Interest}

No potential conflict of interest relevant to this article was reported.

\section{References}

\section{In English}

Bayer, J. K., Sanson, A. V., \& Hemphill, S. A. (2006). Parent influences on early childhood internalizing difficulties. Journal of Applied Developmental Psychology, 27(6), 542559. doi:10.1016/j.appdev.2006.08.002

Beato, A., Pereira, A. I., Barros, L., \& Muris, P. (2016). The relationship between different parenting typologies in fathers and mothers and children's anxiety. Journal of Child and Family Studies, 25(5), 1691-1701. doi:10.1007/ s10826-015-0337-x

Brenning, K., M., Soenens, B., van Petegem, S., \& Kins, E. (2017). Searching for the roots of overprotective parenting in emerging adulthood: Investigating the link with parental attachment representations using an Actor Partner Interdependence Model (APIM). Journal of Child and Family Studies, 26(8), 22992310. doi:10.1007/s10826-017-0744-2

Chorpita, B. F., \& Barlow, D. H. (1998). The development of anxiety: The role of control in the early environment. Psychological Bulletin, 124(1), 3-21. doi:10.1037/00332909.124.1.3 
Cui, L., Morris, A. S., Criss, M. M., Houltberg, B. J., \& Silk, J. S. (2014). Parental psychological control and adolescent adjustment: The role of adolescent emotion regulation. Science and Practice, 14(1), 47-67. doi:10.1080/15295192. 2014.880018

Davis, S., Votruba-Drzal, E., \& Silk, J. S. (2015). Trajectories of internalizing symptoms from early childhood to adolescence: Associations with temperament and parenting. Social Development, 24(3), 501-520. doi:10.1111/sode. 12105

Doh, H. S., \& Falbo, T. (1999). Social competence, maternal attentiveness, and overprotectiveness: Only children in Korea. International Journal of Behavioral Development, 23(1), 149-162. doi:10.1080/016502599384044

Edwards, S. L., Rapee, R. M., \& Kennedy, S. (2010). Prediction of anxiety symptoms in preschool-aged children: Examination of maternal and paternal perspectives. Journal of Child Psychology and Psychiatry, 51(3), 313-321. doi:10.1111/ j.1469-7610.2009.02160.x

Egger, H. L., \& Angold, A. (2006). Common emotional and behavioral disorders in preschool children: Presentation, nosology, and epidemiology. Journal of Child Psychology and Psychiatry, 47(3/4), 313-337. doi:10.1111/j.14697610.2006.01618.x

Eisenberg, N., Taylor, Z. E., Widaman, K. F., \& Spinrad, T. L. (2015). Externalizing symptoms, effortful control, and intrusive parenting: A test of bidirectional longitudinal relations during early childhood. Development and Psychopathology, 27(4), 953-968. doi:10.1017/S0954579415000620

Erikson, E. H. (1963). Childhood and society. Mountain View, CA: Norton.

Gresham, F. M., \& Elliott, S. N. (1990). Social Skills Rating System Manual. Circle Pines, MN: American Guidence Service.

Grolnick, W. S., Caruso, A. J., \& Levitt, M. R. (2019). Parenting and children's self-regulation. In M. H. Bornstein (Ed.). Handbook of parenting: Vol 5. The practice of parenting (3rd ed., pp. 34-64). New York: Routledge.

Howard, M., Muris, P., Loxton, H., \& Wege, A. (2017). Anxietyproneness, anxiety symptoms, and the role of parental overprotection in young South African children. Journal of Child and Family Studies, 26(1), 262-270. doi:10.1007/ s10826-016-0545-z

Kiel, E. J., \& Buss, K. A. (2010). Maternal accuracy and behavior in anticipating children's responses to novelty: Relations to fearful temperament and implications for anxiety development. Social Development, 19(2), 304-325. doi:10. 1111/j.1467-9507.2009.00538.x

Kiel, E. J., \& Buss, K. A. (2014). SI-SHY: Dysregulated fear in toddlerhood predicts kindergarten social withdrawal through protective parenting. Infant and Child Development, 23(3), 304-313. doi:10.1002/icd.1855
Kiel, E. J., Premo, J. E., \& Buss, K. A. (2016). Maternal encouragement to approach novelty: A curvilinear relation to change in anxiety for inhibited toddlers. Journal of Abnormal Child Psychology, 44(3), 433-444. doi:10.1007/ s10802-015-0038-3

Kostelnik, M. J., Soderman, A. K., Whiren, A. P., Rupiper, M., \& Gregory, K. M. (2015). Guiding children's social development \& learning: Theory and skills (8th ed.). Belmont, CA: Cengage Learning.

Laurin, J. C., Joussemet, M., Tremblay, R. E., \& Boivin, M. (2015). Early forms of controlling parenting and the development of childhood anxiety. Journal of Child and Family Studies, 24(11), 3279-3292. doi:10.1007/s10826-015-0131-9

LeMoyne, T., \& Buchanan, T. (2011). Does "hovering” matter? helicopter parenting and its effect on well-being. Sociological Spectrum, 31(4), 399-418. doi:10.1080/02732173.2011.57 4038

Mayer-Brien, S., Turgeon, L., \& Lanovaz, M. J. (2017). Effects of a parent training programme for the treatment of young children with separation anxiety disorder. The Cognitive Behaviour Therapist, 10(12), 1-24. doi:10.1017/ s1754470x17000198

McLeod, B. D., Wood, J. J., \& Weisz, J. R. (2007). Examining the association between parenting and childhood anxiety: A meta-analysis. Clinical Psychology Review, 27(1), 155-172. doi:10.1016/j.cpr.2006.09.002

Moreland, A. D., \& Dumas, J. E. (2008). Evaluating child coping competence: Theory and measurement. Journal of Child and Family Studies, 17(3), 437-454. doi:10.1007/s10826007-9165-y

Mplus (Version 8.3). [Computer software]. Los Angeles, CA: Muthén \& Muthén.

Ooi, L. L., Nocita, G., Coplan, R. J., Zhu, J., \& Rose-Krasnor, L. (2017). Beyond bashful: Examining links between social anxiety and young children's socio-emotional and school adjustment. Early Childhood Research Quarterly, 41(4), 7483. doi:10.1016/j.ecresq.2017.06.003

Perez, C. M., Nicholson, B. C., Dahlen, E. R., \& Leuty, M. E. (2020). Overparenting and emerging adults mental health the mediating role of emotional distress tolerance. Journal of Child and Family Studies, 29(2), 374-381. doi:10.1007/ s10826-019-01603-5

Rapee, R. M. (2009). Early adolescents' perceptions of their mother's anxious parenting as a predictor of anxiety symptoms 12 months later. Journal of Abnormal Child Psychology, 37(8), 1103-1112. doi:10.1007/s10802-009-9340-2

Rubin, K. H., Bowker, J. C., Barstead, M. G., \& Coplan, R. J. (2018). Avoiding and withdrawing from the peer group. In W. M. Bukowisk, B. Laursen, \& K. H. Rubin (Eds.). Handbook of peer interactions, relationships, and groups (2nd 
ed., pp. 322-346). New York: The Guilford Press.

Rubin, K. H., Burgess, K. B., \& Hastings, P. D. (2002). Stability and social-behavioral consequences of toddlers' inhibited temperament and parenting behaviors. Child Development, 73(2), 483-495. doi:10.1111/1467-8624.00419

Rubin, K. H., Coplan, R. J., \& Bowker, J. C. (2009). Social withdrawal in childhood. Annual Review of Psychology, 60(1), 141-171. doi:10.1146/annurev.psych.60.110707.163642

Shaffer, D. R. (2009). Social and personality development (6th ed.). Belmont, CA: Wadsworth.

Spence, S. H., Rapee, R., McDonald, C., \& Ingram, M. (2001). The structure of anxiety symptoms among preschoolers. Behaviour Research and Therapy, 39(11), 1293-1316. doi:10.1016/S0005-7967(00)00098-X

Stewart, S., \& Rubin, K. (1995). The social problem-solving skills of anxious-withdrawn children. Development and Psychopathology, 7(2), 323-336. doi:10.1017/S09545 79400006532

Thomasgard, M., Metz, W. P., Edelbrock, C., \& Shonkoff, J. P. (1995). Parent-child relationship disorder. Part I. Parental overprotection and the development of the Parent Protection Scale. Journal of Developmental and Behavioral Pediatrics, 16(4), 244-250.

West, S. G., Finch, J. F., \& Curran, P. J. (1995). Structural equation models with nonnormal variables: Problems and remedies. In R. H. Hoyle (Ed.), Structural equation modeling: Concepts, issues, and applications (pp. 56-75). New York: Sage Publications.

Wilson, C., \& Hughes, C. (2011). Worry, beliefs about worry and problem solving in young children. Behavioural and Cognitive Psychotherapy, 39(5), 507-521. doi:10.1017/ S1352465811000269

Wood, J. J., Kiff, C., Jacobs, J., Ifekwunigwe, M., \& Piacentini, J. C. (2007). Dependency on elementary school caregivers: The role of parental intrusiveness and children's separation anxiety. Psychology in the School, 44(8), 823-837. doi:10.1002/pits.20268

\section{In Korean}

Byoun, S. B., \& Shin, N. (2021). Maternal overprotection and young children's interactions with peers during play: The mediating roles of social immaturity and withdrawal of children. Journal of Korean Child Care and Education, 17(1), 105-124. doi:10.14698/jkcce.2021.17.01.105

Chung, I. J. (2012). The influences of parental neglect, overprotection and private tutoring on development in early childhood. The Korean Journal of Early Childhood Education, 32(4), 255-278. doi:10.18023/kjece.2012.32.4.012
Chung, K. M., \& Yoon, S. Y. (2015). Development and validation of the Korean-Parental Overprotection Scale: For high school students. The Korean Journal of School Psychology, 12(1), 1-29. doi:10.16983/kjsp.2015.12.1.1

Chung, O. B. (2018). Development in infancy and early childhood (3rd ed.). Seoul: Hakjisa.

Chung, Y. S., \& Park, K. J. (2021). Development and validation of a Maternal Overprotection Scale for Young Children. Korean Journal of Child Studies, 42(3), 359-370. doi:10.5723/ kjcs.2021.42.3.359

Jang, Y. J. (2016). The effects of mothers' anxiety psychological control parenting and attention to achievement on children's responses to a task rechallenge: The mediating effects of self-efficacy (Doctoral dissertation). Retrieved from http://www.riss.kr/ link?id=T14068271

Kim, J. (2020). The influence of maternal limit-setting and overprotective/permissive parenting on preschoolers' externalizing behaviors: A moderated mediation effect of maternal depression and preschoolers' effortful control. Journal of Korean Child Care and Education, 16(3), 99-117. doi:10.14698/jkcce.2020.16.03.099

Kim, L. (2017). Effects of maternal intrusive parenting on mastery motivation in children: Focusing on the moderation role of children's temperament (Doctoral dissertation). Retrieved from http://www.riss.kr/link?id=T14595593

Kim, O. B. (2014). Effects of maternal overprotection and parenting stress on infants' emotional intelligence (Master dissertation). Retrieved from http://www.riss.kr/link?id=T13518213

Kim, S. (2016). Fundamentals and extensions of structural equation modeling: With MPLUS examples. Seoul: Hakjisa.

Lee, H., \& Shin, N. (2020). Preschoolers' behavioral inhibition and anxiety: Mediating effects of maternal overprotective parenting and autonomy support. Journal of Korean Child Care and Education, 16(6), 71-88. doi:10.14698/jkcce. 2020.16.06.071

Lee, J., \& Han, S.-Y. (2019). Effects of maternal differentiation of self, maternal separation anxiety and overprotective parenting on children's separation anxiety. Korean Journal of Child Studies, 40(6), 31-47. doi:10.5723/kjcs.2019.40.6.31

Lee, M., \& Choi, H. (2014). An analysis on the research trend of father's child-rearing involvement. Korean Journal of Youth Studies, 21(7), 307-330.

Lee, S., \& Kang, Y. (2018). The effects of children's ego resilience and leadership and mothers' overprotective behavior on children's peer interaction. The Journal of Korea Open Association for Early Childhood Education, 23(6), 261-278. doi:10.20437/koaece23-6-11

Ryoo, J., \& Shin, N. (2018). The effects of working mothers' separation anxiety, job satisfaction, and overprotective parenting behavior on preschoolers' separation anxiety. 
Journal of Korean Child Care and Education, 14(1), 1-20. doi:10.14698/jkcce.2018.14.01.001

Shin, S. H., \& Lee, W. J. (2016). Childrearing practices perceived as overprotective behaviors for first to third grade levels of elementary school: Focused on cognition of the guardians. Family and Environment Research, 54(5), 475-485. doi:10.6115/fer.2016.037

\section{ORCID}

Young Sun Chung http://orcid.org/0000-0001-9360-4927

Received August 23, 2021

Revision received September 30, 2021

Accepted October 14, 2021 